\title{
Conceptual Misunderstanding: On the Interplay of Understanding and Misunderstanding in Geometry
}

\author{
Anass Bayaga ${ }^{1, *}$, Michael J. Bossé ${ }^{2}$ John Sevier² \\ ${ }^{1}$ Senior Secondary Education, Faculty of Education, Nelson Mandela University, Port Elizabeth, South Africa \\ ${ }^{2}$ Mathematical Sciences, Appalachian State University, USA
}

Received April 6, 2021; Revised June 1, 2021; Accepted June 15, 2021

\begin{abstract}
Cite This Paper in the following Citation Styles
(a): [1] Anass Bayaga, Michael J. Bossé, John Sevier, "Conceptual Misunderstanding: On the Interplay of Understanding and Misunderstanding in Geometry," Universal Journal of Educational Research, Vol. 9, No. 8, pp. 1511 - 1520, 2021. DOI: 10.13189/ujer.2021.090803.
\end{abstract}

(b): Anass Bayaga, Michael J. Bossé, John Sevier (2021). Conceptual Misunderstanding: On the Interplay of Understanding and Misunderstanding in Geometry. Universal Journal of Educational Research, 9(8), 1511 - 1520. DOI: 10.13189/ujer.2021.090803.

Copyright $\odot 2021$ by authors, all rights reserved. Authors agree that this article remains permanently open access under the terms of the Creative Commons Attribution License 4.0 International License

\begin{abstract}
Analyzing the communication and work of high school geometry students through error-prone topics such as transformations, constructions and employing various thinking processes such as factual and procedural knowledge could reveal insight to students understanding of Geometry. Such a body of work [1, 4, 5], could reveal suitable or unsuitable considerations of a topic combined with suitable or unsuitable uses of a thinking process thereby producing suitable or unsuitable conclusions. Directed by the objective of the study, three high school geometry students' interpretations were analyzed in order to explore: (1) connections among topics and thinking processes; (2) relationships among suitable and unsuitable uses of the topic and thinking processes; and (3) whether unsuitable uses of topics and unsuitable thinking processes can yet lead to suitable understanding. The results revealed no definitive association among some topics and some thinking processes, whether suitable or unsuitable in either realm. Unsuitable applications of factual, procedural, and conceptual knowledge were not associated simply with the lack of these thinking processes, at times. However unsuitable thinking processes were present, deliberate, purposive, and not absent. By implication, there is a need for more studies regarding student use and misuse of thinking processes regarding other mathematical subjects.
\end{abstract}

Keywords Misunderstanding, Geometry, Factual Knowledge, Conceptual Knowledge and Procedural Knowledge

\section{Introduction}

For decades, Bloom's Taxonomy and Bloom's Revised Taxonomy have been considered seminal constructs to consider human thought and cognitive activities $[1,4]$. The types of knowledge used in cognition (factual, procedural, and conceptual) have been investigated through many dimensions and among many different audiences.

Errors associated with learning mathematics in general [7] and geometry in particular [15] have been investigated through the years. Özere [15] identified four categories of errors and misunderstandings in geometry learning: measures, angles, transformation, and construction of 3D shapes. Others have considered types of errors students make regarding Bloom's Revised Taxonomy of Knowledge (i.e., factual, procedural, and conceptual knowledge) [10, 21]. However, many have treated factual, procedural, and conceptual errors and misunderstandings as synonymous with the absence of these types of knowledge. In other words, errors in conceptual understanding are seen as a lack of conceptual understanding. Together, there is a need to reinvestigate both the understanding of factual, procedural, and conceptual errors and determine if there are associations between factual, procedural, and conceptual understanding and misunderstandings and suitable and unsuitable applications of measures, angles, transformation, and constructions. This study seeks to 
begin to address this gap in the literature and investigate these associations.

Based on the fact that the current study sought to examine conceptual misunderstanding, thus the interplay of understanding and misunderstanding in Geometry, it was inclined to examine taxonomy of cognition. In response, the revised version as articulated in the literature review section by Anderson and Krathwohl [1] was used. Thus, in addressing the topic, the authors were directed by the taxonomy of the types of knowledge used in cognition as elaborated further in the literature review.

\section{Literature Review}

The revision by Anderson and Krathwohl [1] led to a new and separate taxonomy of the types of knowledge used in cognition. These included:

- factual knowledge (knowledge of terminology, specific details, and elements);

- procedural knowledge (knowledge of subject-specific skills, algorithms, techniques, and methods and knowledge of criteria determining when to use appropriate procedures);

- conceptual knowledge (knowledge of classification, categories, principles, generalizations, theories, models, and structure); and

- metacognitive knowledge (knowledge about strategies, cognitive tasks, and self).

Only a few years prior to the Revised Bloom's Taxonomy, de Jong and Ferguson-Hessler [9] opined regarding the significance of factual, procedural, and conceptual knowledge. This was soon followed by further discussions of this quickly accepted taxonomy of knowledge $[13,16]$. Since then, considerations of the framework including factual, procedural, and conceptual knowledge, have saturated educational research and taken its position of importance in understanding cognition.

Identifying and addressing student errors is considered vital in analyzing students' mathematical understandings (and misunderstanding). Some authors [7: 16] summarize research regarding students' mathematical errors and error patterns with the following points:

- Typically, students' mathematical errors fall into three broad categories: factual, procedural, and conceptual. Each of these errors is related either to a student's lack of knowledge or a misunderstanding [10,20].

- Not every error is the result of a lack of knowledge or skill. Sometimes, a student will make a mistake simply because he was fatigued or distracted (i.e., careless errors) [10].

- Procedural errors are the most common type of error [20].

- Because conceptual and procedural knowledge often overlaps, it is difficult to distinguish conceptual errors from procedural errors [21, 20].
It is very reasonable that, if factual, procedural, and conceptual knowledge define much of knowledge and reasoning, then errors would also take these forms $[10,20$, 21]. In the context of geometry learning, it is recognized that student errors are not synonymous with students' knowing and using appropriate vocabulary knowledge associated with geometry [20]. There remain questions regarding how students' understanding and misunderstanding affect their cognition of angles [15].

There is an abundance of literature regarding student misconceptions and errors in the learning of geometry. For instance, Biber, Tuna, and Korkmaz [3] focus primarily on levels of thought processes and mistakes, revealing that learners tend to rely more on the shapes of geometric objects than the associated properties held by the geometric structures. While some learners attempt to identify some geometric properties within structures, many cannot correlate appropriate properties within a given problem's associated solutions. The authors [3] claim that this phenomenon has received scant attention.

In geometry learning, there is also an inclination to generalize the validity of one geometric condition over a number of different - and often inappropriate - cases. This leads to miscomprehensions among properties and cases $[3,20]$ and research which convolutes issues allied with misconceptions and errors in geometry cognition [3]. Since geometric concepts are generally constructed visually, it remains unclear why it is problematic for some to learn geometry. Some studies have attempted to characterize the difficulty of understanding geometry based on conceptual knowledge, factual, and procedural knowledge or lack thereof $[2,3,11,22]$. However, the problematic nature of this reasoning is that, for instance, conceptual knowledge is dependent on a variety of variables such as "... recognizing a concept, knowing the definition, name of a concept as well as seeing the mutual transitions and relations among concepts" [3: 51].

Additionally, quite a few studies have wondered why, for instance, geometry concepts are taught and presumably learned via rote approaches $[3,15,18,19]$. It is not also firmly known why for instance, “....properties, scopes, associations, and meanings contained in geometric expressions cannot be taught satisfactorily" [3: 51]. There remains work needed to unpack why some learners tend to extend or generalize specific concepts, rules, and expressions beyond their appropriate applications. While there is limited research regarding how these affect cognitions in geometry learning, some have investigated how to identify and address the conception of geometry errors and misunderstanding $[6,15]$.

Özere [15] investigated means by which to identify and address errors and misunderstandings in geometry learning through an analysis and synthesis of seventh $\left(7^{\text {th }}\right)$ grade geometry concepts into four categories. In no precise order, these $7^{\text {th }}$-grade concepts include: measures, angles, transformation, and construction of 3D shapes. 
Notably, Özere [15] states both (A) that research has found that these categories and concepts are those in which students often struggle to learn and understand and (B) that research yet needs to determine why students have difficulties in these areas. For instance, it is still yet to be known why concepts such as metric and imperial measure, perimeter and area of a rectangle, and area of a triangle, parallelogram, and trapezium are still yet to be known regarding the category of measures challenging concepts for learners to grasp [15]. For the category angles, what is still unclear include "properties of a triangle, angles in a parallel line, properties of a quadrilateral, properties of a polygon, congruent shapes and 3-D shapes" [15: 27]. Similarly, while it is well established that students struggle with concepts in the category of transformations (i.e., combinations of transformations, symmetry, and enlargement), scant research delineates why this is so. According to Özere [15: 27], precisely why students struggle with the construction of 3D shapes (e.g., the construction and "...bisection of triangles and perpendiculars, loci, surface area and volume of a cuboid" is also not resolutely researched.

Generally speaking, error analysis seeks to identify types and reasons associated with any aspect of mathematics [6]. Until now, much of what is known is the general sense of how to identify procedures students undertake suitably [6]. Beyond that, there is still a dearth of evidence as to why, for instance, students make some types of errors in measures, angles, transformation, and construction of $3 \mathrm{D}$ shapes $[6,15]$. There is seemingly insufficient contemporary research outlining whether errors are a once-off event or continuous misapplication of concepts and procedures regarding measures, angles, transformation, and construction of 3D shapes. While some propound that misconceptions may be enhanced or minimized through appropriate teaching approaches [6], it is yet unknown to what extent this applies to the learning of measures, angles, transformation, and construction of 3D shapes.

\section{Problem Statement}

In this study, we conjoin the following:

- the Revised Bloom's Taxonomy [1] in respect to factual, procedural, and conceptual knowledge;

- the recognition that most mathematical errors fall in the nature of factual, procedural, and conceptual knowledge $[6,10,20,21]$ and

- that geometry misunderstandings fall into four categories (measures, angles, transformation, and construction) [15].

\section{The Objective of the Study}

Using the topics of angles, measurement, transformations, and constructions and the thinking processes of factual, procedural, and conceptual knowledge, we analyze some transcripts of student communication to investigate:

- connections among topics and thinking processes;

- relationships among suitable and unsuitable uses of the topic and thinking processes; and

- whether unsuitable uses of topics and unsuitable thinking processes can yet lead to suitable understanding.

\section{Methodology}

\section{General Background}

Based on the objective, the current study employed a case study designed to explore and interpret participants' communications regarding geometric ideas. Specific concepts involved in the case study included the use of topics in angles and measurement. As coordinated and directed by the objective of the study, other topics included transformations, and constructions and the thinking processes of factual, procedural as well as conceptual knowledge. In effect, the current study analyzed the transcripts of respondents' interpretations in order to explore: (1) connections among topics and thinking processes (2) relationships among suitable and unsuitable uses of topic and thinking processes; and (3) whether unsuitable uses of topics and unsuitable thinking processes can yet lead to suitable understanding. Involved in two distinct scenarios, three different students were observed to investigate individual and cross-case notions. Thus, the comparison of results was in accordance with suitable and non-suitable responses

\section{Participants, Tasks, and Instrumentation}

Participating students included three 16-year-old high school geometry students from a school in the Southeastern United States. Using a task-based interview design, the student participants were asked to complete their respective research tasks. We denote these students as Student 1 (S1), Student 2 (S2), and Student 3 (S3). In one scenario, Student 1 and Student 2 are involved in a discussion regarding the area of a trapezoid. In another scenario, Student 3 is interacting with the classroom teacher regarding the area of a rhombus. While this interaction is recorded, the teacher's communication is not analyzed as data for this study. Consequently, included in two distinct setups, three separate students were examined to explore individual and cross-case notions of: (1) connections among topics and thinking processes (2) relationships among suitable and unsuitable uses of topic and thinking processes; and (3) whether unsuitable uses of topics and unsuitable thinking processes can yet lead to suitable understanding. Noting that the comparison of 
results was in accordance with suitable and non-suitable responses from the students in line with the objectives of the study.

\section{Sample Selection Nature of Sample}

The student participants were selected at random. They agreed to participate and were provided with no incentive whatsoever to participate. The participants in this study were high school geometry students in North Carolina, the U.S. Two distinct groups of students were observed. All three student participants were in the same class, instructed by the same teacher, and had experienced similar learning activities throughout the course. All students were also from the same school system and had all taken the same courses in previous years. Thus, common to all students' knowledge included: topics in angles, measurement, transformations, and constructions.

\section{Justification of Sample Size}

For the most part in research, sample sizes in qualitative studies tend to be unjustified, characteristically termed as insufficient if small, which are sometimes even considered as a limitation. Due to the nomothetic nature particularly associated with natural sciences, for the small sample size in qualitative research, constructs such as validity or generalizability tend to be threatened. Thus, in justifying the use of a small sample size for the current study (which was three (3)), the authors anchored the decision on the recommendation of Vasileiou, Barnett and Thorpe (2018). While sample size justification is limited in qualitative studies, Vasileiou et al. (2018) demonstrated that in a qualitative study, adequacy of sample size is not contingent upon the number of valid respondents. The defense of sample size is key; however, the principle of saturation and pragmatic considerations must be the cornerstone. Consequently, three (3) participants, who were used in the current study, provided the desirable saturation as well as the pragmatic accounts or responses in addressing the research problem and objectives.

\section{Data and Analysis}

Participants were videotaped as they completed their tasks. Data analysis followed a number of stages: First, the audio-video recordings were transcribed. Second, employing discourse analysis, all data (audio-video recordings, participant written work, and transcripts) were reviewed to identify themes $[5,8]$ and data were sorted into those categories. The researchers particularly searched for student understanding of three ideas based on the objective. Recalling that the comparison of results was in accordance with suitable and non-suitable responses from the students in line with the objectives of the study: Thus, the codes developed and employed in this analysis include those regarding: (1) connections among topics and thinking processes (2) relationships among suitable and unsuitable uses of the topic and thinking processes; and (3) whether unsuitable uses of topics and unsuitable thinking processes can yet lead to suitable understanding. This was achieved through the process of check-coding [14]. The researchers' initial coding structures were then compared and contrasted, leading to recognition of similar, different, and missing constructs, and researchers were able to reach a consensus $[23,24,25,26]$. Developing this list of observed student interpretations extends the majority of the literature regarding students' understanding of geometry. Together with the results, the consensus notes are provided in the below reported transcripts in order to provide the reader more insight into the analysis, coding, and results associated with this study.

\section{Results and Data Sources}

Student interactions were recorded via video and audio and written work was preserved. Recordings were transcribed. To investigate participant thinking and understanding, this study employed the qualitative research methodologies of case studies together with discourse analysis $[5,8,14,25,26]$ to analyze and synthesize the transcript data. The data was coded as follows:

- Observable occurrences of participants' suitably considering angles, measurements, transformations, or constructions were respectively coded as A, M, T, or C.

- Observable occurrences of participants unsuitably considering angles, measurements, transformations, or constructions were respectively coded as $\sim \mathrm{A}, \sim \mathrm{M}$, $\sim \mathrm{T}$, or $\sim \mathrm{C}$.

- Observable occurrences of participants suitably using procedural, factual, or conceptual knowledge were respectively coded as $\mathrm{P}, \mathrm{F}$, or $\mathrm{U}$.

- Observable occurrences of participants' unsuitability using procedural, factual, or conceptual knowledge were respectively coded as $\sim \mathrm{P}, \sim \mathrm{F}$, or $\sim \mathrm{U}$.

The transcripts were independently coded by two researchers. Then, both researchers collaborated in comparing and contrasting their coding structures, employing the process of check-coding (Miles \& Huberman, 1994) to reach a consensus on the analysis of the transcripts. Summaries of individual participants thinking and more global aspects among the participants in respect to the coded characteristics were developed. In the following transcripts, students are denoted by S1, S2, and $\mathrm{S} 3$ and the teacher by $\mathrm{T}$. The codes for the respective characteristics for topics and thinking processes are embedded in the transcripts.

\section{On the Area Formula of a Rectangle}

Section $1 \mathrm{~A}$

S1: Hey, I think I have something new. We know that if 
we rotate a triangle around a midpoint of aside, we get a parallelogram. [T/P, U]

$\mathrm{S} 2$ : By $180^{\circ}$. [M/P]

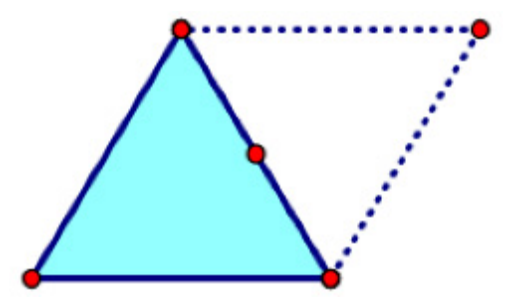

S1: Right. Also, if we cut a triangle parallel to its base, we get a trapezoid. So, then I started playing with pieces of paper and I came up with something cool. [T, C/]

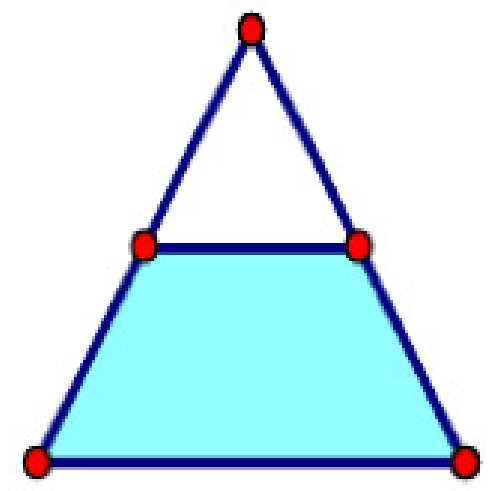

If I rotate a triangle with a trapezoid inside, I get this. $[\mathrm{T}, \mathrm{C} / \mathrm{P}]$

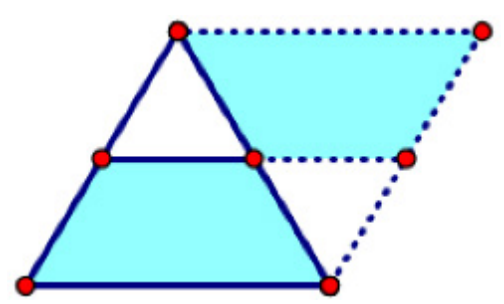

And if I shift the triangle down some it makes this. And so, rotating a trapezoid on one of its sides makes a parallelogram. $[\mathrm{T}, \mathrm{C} / \mathrm{P}, \mathrm{F}]$

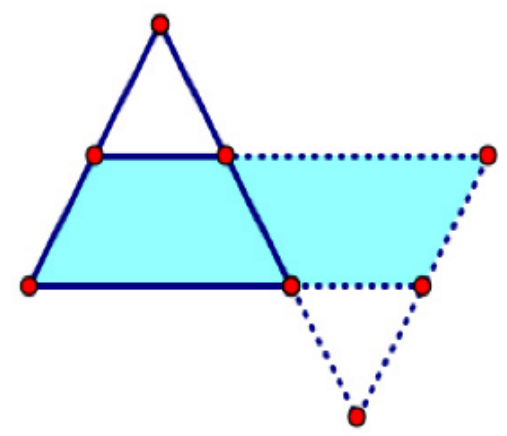

S2: By one of its nonparallel sides and by $180^{\circ}[\mathrm{A} / \mathrm{F}]$

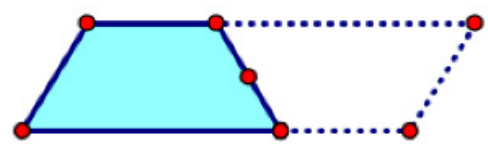

S1: Right. So, if we start with any trapezoid and do that rotation, we get a parallelogram. $[\mathrm{T}, \mathrm{C} / \mathrm{P}, \mathrm{C}, \mathrm{U}]$

[Thus far, we can see that S1 has affinities for transformations and constructions and seems to generate understanding from experimenting with such. S1 demonstrates glimpses of conceptual understanding, but this conceptual understanding seems to be the product of procedural practices. Still unknown is whether conceptual understanding led to the construction and transformation techniques S1 employed. This raises the question, do procedural practices lead to conceptual understanding or vice versa? S2 seems more focused on angles, measurements, and facts than on conceptual understanding. S2 allows S1 to perform all the constructions and transformations. There is no indication as to whether S2 could do this independently.]

Section 1B

S2: So?

$\mathrm{S} 1$ : The cool part is the area. What is the area formula for a trapezoid? [M/F, U]

S2: Half height times big B plus little b. [/F, P]

$\mathrm{S} 1$ : That's right. But why?

S2: I'm not sure.

$\mathrm{S} 1$ : It's right here. Look. Once we have a parallelogram and we know that the area of the parallelogram is base times height, we just need to look at our parallelogram. Look at the base. It is big $B$ plus little $b .[\mathrm{M} / \mathrm{F}, \mathrm{U}]$

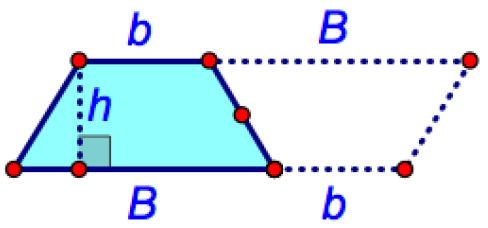

$\mathrm{S} 2$ : But we have the same height, not half height. [ $\mathrm{M} /]$ S1: Yes, but we have a parallelogram twice as large as the trapezoid. So, the half height would be right for the trapezoid. [T, M/U]

S2: That's cool.

S1: What's even cooler is that we don't need to double the trapezoid. [T, C/U]

S2: What do you mean?

$\mathrm{S} 1$ : If we cut the trapezoid in half parallel to the bases, and rotate the top part, we get this. It's still a parallelogram with a base of big $B$ plus little $b$. But now its height is only half $h$. It works. [T, C, M/U, P]

S2: Why didn't we see this in class? Did you just get this by playing around? $[/ \sim \mathrm{P}]$

[S2 understands and remembers facts and procedures through measurements and angles. There is, however, no evidence of conceptual understanding in his/her articulations. On one occasion each, S2 unsuitably employs/understands measurement and procedural knowledge. S1, continues to demonstrate some conceptual understanding. Instead of previously hypothesized, it 
seems to be confirmed that conceptual understanding is leading to suitable procedures.]

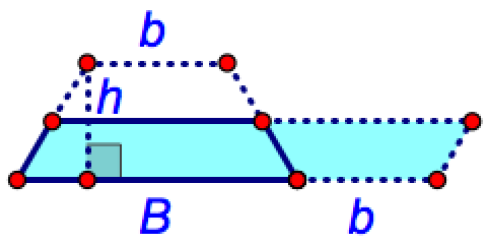

On Area Misunderstanding

Section 2A

$\mathrm{T}$ : Find the area of the figure.

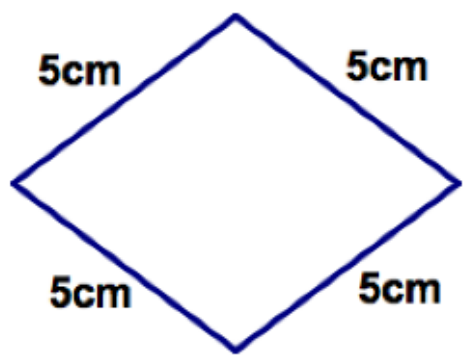

S3: 25 .

T: That was fast. How did you get 25 ?

S3: 5 times $5 .[\mathrm{M} / \sim \mathrm{P}]$

T: Let's say that 25 is suitable. 25 what?

S3: Oh, 25 square centimeters. $[\mathrm{M} / \sim \mathrm{P}]$

T: So, why do you say 5 times 5 ?

S3: It looks like a parallelogram. So, the area is base times height. $[\sim \mathrm{C} / \mathrm{F}]$

[S3 demonstrates a focus on measurements, constructions, and procedural knowledge - albeit with faulty notions on each. Simultaneously, s/he demonstrates some suitable thinking/application of measurements and facts. No observation of conceptual understanding is yet evident.]

\section{Section 2B}

$\mathrm{T}$ : Which is the base and which is the height?

S3: Well, any two sides that come together. Wait. I think that it needs to be the two lowest sides. [C/ P]

T: Why?

S3: Because that angle looks more right than the side angles. $[\mathrm{M}, \sim \mathrm{A} / \mathrm{F}, \sim \mathrm{P}]$

$\mathrm{T}$ : More right?

S3: Closer to $90^{\circ}$. $[\mathrm{M} / \mathrm{F}]$

T: Why do you want it closer to $90^{\circ}$ ?

S3: The base and height are supposed to be perpendicular. [A, C/F]

$\mathrm{T}$ : But these aren't perpendicular.

S3: But they are the closest ones. [A, M/ P]

$\mathrm{T}$ : Will that give you 25 square centimeters?

S3: I think that it will give me just a little less or a little more than 25 . But probably pretty close. $[\mathrm{M}, \mathrm{C} / \mathrm{F}, \sim \mathrm{U}]$ The angle doesn't look too far from $90^{\circ}$. [A, M/]
[S3 demonstrates a combination of understanding and misunderstanding. Indeed, s/he demonstrates misunderstanding regarding angles in the use of both procedural knowledge and conceptual understanding. While s/he knows that base and height must be perpendicular, $\mathrm{s} / \mathrm{he}$ is willing to approximate measurements and visually assume perpendicularity when sufficiently close to 90 degrees. S/he focusses on angles and measurements factual understanding. Interestingly, s/he only employs conceptual understanding once in an unsuitable manner. While s/he conceptually understands that departure of the investigated angle from 90 degrees could alter the area of the rhombus, she unsuitably believes that it may increase it beyond $25 \mathrm{~cm}^{2}$.]

Section $2 \mathrm{C}$

T: What if I told you that the actual area is 24 square centimeters?

S3: Then I am right, or at least close enough. [/ P, $\sim \mathrm{U}]$

$\mathrm{T}$ : Close enough?

S3: Well I said that it could be a little less than 25. [M/]

T: Could it be a lot less than 25 square centimeters?

S3: If it was flattened out more. But it isn't. The angle is almost $90 .[\mathrm{C} / \mathrm{U}]$

$\mathrm{T}$ : What if I told you that the measure of that bottom angle is over $106^{\circ}$ ?

S3: That's kinda high. It's bigger than it looks. [A, $\mathrm{M} / \mathrm{U}]$

T: So, what about your 5 times 5 ?

S3: I don't think that we should use that. [/P]

$\mathrm{T}$ : Any ideas?

S3: Can we straighten it out so that the angle is 90 ? $[\sim \mathrm{C}$, $\sim \mathrm{T} / \sim \mathrm{P}]$

$\mathrm{T}$ : Then that would give us an area of 25 square centimeters. And that is not what we have.

S3: But we don't have any other measurements to use. $[\mathrm{M} / \mathrm{P}]$

T: If you could have other measurements, what would you use?

S3: I want something at $90^{\circ}$. [A, M, C/P, U]

[S3 demonstrates instances of procedural and conceptual understanding and misunderstanding regarding suitable consideration of angles, measures, constructions, and transformations. However, codes in this section varied widely (e.g., $[/ \sim \mathrm{P}, \sim \mathrm{U}],[\mathrm{C} / \mathrm{U}],[\mathrm{A}, \mathrm{M} / \mathrm{U}],[\sim \mathrm{C}, \sim \mathrm{T} / \sim \mathrm{P}]$, $[\mathrm{M} / \mathrm{P}]$, and $[\mathrm{A}, \mathrm{M}, \mathrm{C} / \mathrm{P}, \mathrm{U}])$. This demonstrates that, for $\mathrm{S} 3$, procedural knowledge and conceptual understanding are not directly associated with whether s/he was considering angles, measures, constructions, or translations and that there were often inconsistencies among these. While s/he demonstrates an instance of misunderstanding while considering a transformation, $\mathrm{s} /$ he shows both suitable and unsuitable application of constructions.]

Section 2D 


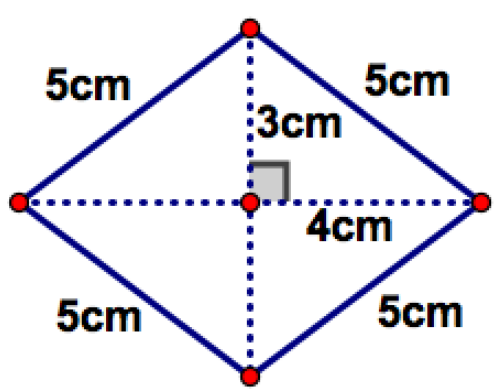

T: What if I gave you this information?

S3: You're trying to trick me. Those are on the inside. That won't work. [/F, P ]

T: Why?

S3: One, or at least one, of the measurements needs to be on the outside. $[\mathrm{M} / \sim \mathrm{P}]$

T: Why?

S3: That's how we do it.

$\mathrm{T}$ : Can we try it this way?

S3: That would give me an area of $48 .[\sim \mathrm{M} / \sim \mathrm{P}]$

T: Why 48 ?

S3: The sides at the 90 are 6 and 8.6 times 8 is 48 . And you said that it is 24 . [M/ P]

T: I'm telling the truth. It is 24 square centimeters. Can you adjust your reasoning?

S3: I'm not sure if I see two big triangles or four small triangles. [T/F]

$\mathrm{T}$ : Does it matter?

S3: The big triangle is 6 times 8 divided by 2 . That's 24 . $[\mathrm{M} / \mathrm{P}]$

T: Which triangle is 6 times 8 ?

S3: The top big one. $[\mathrm{C} / \mathrm{F}]$

$\mathrm{T}$ : What are its dimensions?

S3: 8 on the horizontal and, oh, only 3 on the vertical. So that's 8 times 3 divided by 2 . 24 divided by 2 is 12 . And I guess that's the same on the bottom triangle. So, that gives $\mathrm{s} 24$. $[\mathrm{M} / \mathrm{F}, \mathrm{P}]$

T: So, what did you learn?

S3: At first, we did not really have enough information. But after you put those lines in, we had a 90, so we could multiply something. [C/P]

$\mathrm{T}$ : That's great.

S3: But what about the area?

T: What do you mean?

S3: How do we know that's the area of the whole shape. Those measures aren't on the outside. I'll do it, but I'm not sure that I get it. $[\sim \mathrm{M} / \mathrm{F}, \sim \mathrm{P}]$

[S3 demonstrates a lack of conceptual understanding and primarily employs factual and procedural knowledge. $\mathrm{S} / \mathrm{he}$ continues to employ measurements, transformations, and constructions. However, the selected strings of codes $[\mathrm{M} / \sim \mathrm{P}],[\sim \mathrm{M} / \sim \mathrm{P}]$, and $[\mathrm{M} / \mathrm{P}]$ and $[\mathrm{M} / \mathrm{F}, \mathrm{P}]$ and $[\sim \mathrm{M} / \mathrm{F}, \sim \mathrm{P}]$ reveal much. Notably, the combinations (MP, $\mathrm{M} \sim \mathrm{P}$, and $\sim \mathrm{M} \sim \mathrm{P}$ ) and (MF and $\sim \mathrm{MF}$ ) further reveal that procedural and factual understanding and misunderstanding are not associated with considerations of measurement.]

\section{Discussion}

\section{Overview}

Stripping away all the contextual transcripts and retaining only the analytic codes, a structure arises for each respective student participant:

S1: [T/P, U]; [T, C/] [T, C/P] [T, C/P, F]; [T, C/P, C, U]; $[\mathrm{M} / \mathrm{F}, \mathrm{U}] ;[\mathrm{M} / \mathrm{F}, \mathrm{U}] ;[\mathrm{T}, \mathrm{M} / \mathrm{U}] ;[\mathrm{T}, \mathrm{C} / \mathrm{U}] ;[\mathrm{T}, \mathrm{C}, \mathrm{M} / \mathrm{U}, \mathrm{P}]$

$\mathrm{S} 2:[\mathrm{M} / \mathrm{P}] ;[\mathrm{A} / \mathrm{F}] ;[/ \mathrm{F}, \mathrm{P}] ;[\sim \mathrm{M} /] ;[/ \sim \mathrm{P}]$

S3: $[\mathrm{M} / \sim \mathrm{P}] ; \quad[\mathrm{M} / \sim \mathrm{P}] ;[\sim \mathrm{C} / \mathrm{F}] ; \quad[\mathrm{C} / \sim \mathrm{P}] ; \quad[\mathrm{M}, \sim \mathrm{A} / \mathrm{F}, \sim \mathrm{P}]$; $[\mathrm{M} / \mathrm{F}] ;[\mathrm{A}, \mathrm{C} / \mathrm{F}] ;[\mathrm{A}, \mathrm{M} / \sim \mathrm{P}] ;[\mathrm{M}, \mathrm{C} / \mathrm{F}, \sim \mathrm{U}][\mathrm{A}, \mathrm{M} /] ;[/ \sim \mathrm{P}, \sim \mathrm{U}]$; $[\mathrm{M} /] ; \quad[\mathrm{C} / \mathrm{U}] ; \quad[\mathrm{A}, \mathrm{M} / \mathrm{U}] ; \quad[/ \mathrm{P}] ; \quad[\sim \mathrm{C}, \sim \mathrm{T} / \sim \mathrm{P}] ; \quad[\mathrm{M} / \mathrm{P}] ;$ $[\mathrm{A}, \mathrm{M}, \mathrm{C} / \mathrm{P}, \mathrm{U}] ;[/ \mathrm{F}, \sim \mathrm{P}] ;[\mathrm{M} / \sim \mathrm{P}] ;[\sim \mathrm{M} / \sim \mathrm{P}] ;[\mathrm{M} / \sim \mathrm{P}] ;[\mathrm{T} / \mathrm{F}] ;$ $[\mathrm{M} / \mathrm{P}] ;[\mathrm{C} / \mathrm{F}] ;[\mathrm{M} / \mathrm{F}, \mathrm{P}] ;[\mathrm{C} / \mathrm{P}] ;[\sim \mathrm{M} / \mathrm{F}, \sim \mathrm{P}]$

Each of these structures demonstrates its idiosyncrasies. For instance, $\mathrm{S} 1$ is more able to make positive use of constructions and transformations. S2 and S3 focus more on angles and measurements, but often with limited understanding. Indeed, it can clearly be seen that either positive (A, M, T, and $\mathrm{C}$ ) or negative $(\sim \mathrm{A}, \sim \mathrm{M}, \sim \mathrm{T}$, and $\sim \mathrm{C}$ ) uses of each focus (angles, measurement, transformations, and constructions) is possible. In other words, information or misinformation regarding angles, measures, transformations, and constructions can be used to come to either right or wrong conclusions $[1,2,3,4,11$, $12,16]$.

In respect to procedural knowledge, factual knowledge, and conceptual understanding, it can be seen that each of these can also be used either in the positive $(\mathrm{P}, \mathrm{F}, \mathrm{U})$ or negative $(\sim \mathrm{P}, \sim \mathrm{F}, \sim \mathrm{U})$; they can lead to either positive or negative conclusions. Again, the three student participants experience these dimensions differently. S1 generally applies conceptual understanding to suitable ideas. However, S3 used both suitable and unsuitable conceptual understanding leading to both suitable and erroneous results.

Altogether, this makes distinguishing mathematical understanding from misunderstanding possibly more complex than previously recognized. It is generally accepted that misconception or difficulty to understand arises when there is a skip of step, process, or idea $[1,2,4$, $7,10,11,12]$. However, this may be a far too simplistic perspective. Additionally, in respect to distinguishing between understanding and misunderstanding, it is equally overly simplistic to consider dimensions of thinking as ordered by sophistication such as:

angles $\leq$ measurement $<$ transformations $<$ constructions

or

factual knowledge $<$ procedural knowledge $<$ conceptual understanding.

This type of ordering assumes that goals for student learning should be to get students to higher levels of thinking. This, in turn, implies that higher levels of 
thinking lead to right thinking and suitable answers.

In the transcripts, we see examples where any of these dimensions of thinking could lead to either understanding or misunderstanding. For instance, let us revisit a portion of the second transcript. In Section $2 \mathrm{C}$ of the transcript, dimensions of translations, constructions, and conceptual understanding - all assumedly higher levels of thinking lead to understanding, incomplete ideas, and even misunderstandings.

Similarly, in Section 2B of the transcript, we see examples where assumedly lower-level thinking (e.g., angles, measurement, procedural knowledge, and factual knowledge) leads to understanding, incomplete ideas, and even misunderstandings. In Section 1B of the transcript, S2 rightly recalls the area formula for a trapezoid using factual and procedural knowledge. While many may perceive that these dimensions of thinking are relatively base, they yet produce suitable and usable information.

Altogether, the transcripts and coding demonstrate that suitable or unsuitable considerations of a topic combined with suitable or unsuitable uses of a thinking process produce suitable or unsuitable conclusions, albeit in possibly unpredictable forms. Nevertheless, the number of forms is calculable (see Figure 1).

If we consider only one topic associated with one thinking process, we can calculate (four topic choices) $\times$ (three thinking process choices) $\times$ (two consideration options) $\times$ (two conclusion options), leading to 48 combinations. Notably, however, a single instance may often incorporate more than one topic and more than one thinking process. Thus, the number of possible combinations is much higher.

The observation that even unsuitable reasoning can lead to suitable understanding may in some way strain the fabric of what previous research recognizes about mathematical misunderstandings. For instance, while Brown, Bossé, and Chandler [6] detail 18 types of errors that students can perform when problem-solving in a dynamic math environment, as with other researchers, mathematical errors are most typically defined as an absence of particular reasoning. In this current study, we recognize that mathematical misunderstanding can be born from types of reasoning - rather than merely the lack of such.

Furthermore, the literature is replete with discussions that regard factual knowledge and procedural knowledge in the pejorative - as is less than, rather than different from conceptual understanding. Indeed, it must be wondered if conceptual understanding is at all possible completely devoid of factual and procedural knowledge.

Through the study transcripts, S1 demonstrates and recognizes rotating a trapezoid on one of its sides makes a parallelogram. The student further indicates that and notes the notion reflecting that any rotated trapezoid gives a parallelogram. This suggests a level of conceptual understanding. Conversely, the inability of S3 to readily respond to the question of why s/he wants the angle closer to 90 degrees can be seen as an incomplete understanding regarding construction and perpendicularity. It is also fair to suggest from the text that S3 demonstrates a lack of assimilation of properties of quadrilaterals.

There is evidence that S2 and S3 struggled with the inability to suitably communicate ideas together with a lack of readily available explanation (e.g., S3 in respect to the area); this, in part, could be related to limited conceptual knowledge $[1,3,4]$. Connected to procedural knowledge, there is a need to understand pertinent concepts and appropriate applications [3, 4]. In this regard, whether procedurally or conceptually, learners should know what and how ideas and principles relate to others. Inferring from the student's work, conceptual errors arose when the student demonstrated a lack of understanding of the applicable ideas and principles related to 'areas' and 'angles' $[1,3,4]$.

The lack of understanding of ideas and principles results in a discontinuity of progress or sometimes overgeneralization $[1,3,4,6]$. This could be seen in S3's discussion of a parallelogram (e.g., "....it looks like a parallelogram. So, the area is base times height", “...well, any two sides that come together. Wait. I think that it needs to be the two lowest side" and "...because that angle looks more right than the side angles."). The lack of conceptual knowledge also demonstrated overspecialization, where the learners advance a narrow set of definitions, rules, and even the appropriateness of its application (e.g., when the teacher asked S3 why the area would be 48, S3 responded, "the sides at the 90 are 6 and 8.6 times 8 is 48 " and "I'm not sure if I see two big triangles or four small triangles.")

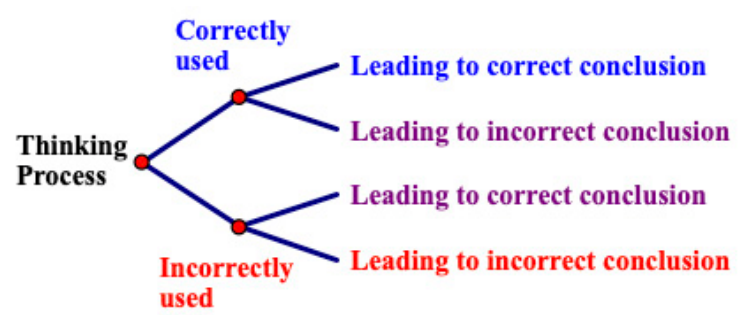

Figure 1. Tree diagrams for results of suitable and unsuitable considerations of topics using suitable or unsuitable applications of thinking processes. 
Research [7] opine that insufficient studies have been conducted in relation to types of errors in measures, angles, transformation, and construction of 3D shapes. Earlier investigations also suggest that there are other errors that are once-off events, while others are of continuous misapplication $[2,12]$. Even within the limited transcripts in this current study, both once-off and continuous misunderstandings and misapplications are observed. Unfortunately, the literature most often frames these through a lack of prior knowledge $[1,2,4,6,17]$.

Previous research suggests that factual, procedural, and conceptual knowledge contribute a great deal to geometric reasoning and that misconceptions in geometry lead to learning levels, mistakes, and convolutions of ideas and principles related to misconceptions and errors $[1,3,4,10$, $12,1520,21]$. However, this study seems to extend this in a number of dimensions. These dimensions are reiterated in the following Conclusions and Implications section.

\section{Conclusions}

In the context of study participants considering the topics of angles, measurements, transformations, and constructions employing factual, procedural, and conceptual knowledge, evidence suggests that suitable or unsuitable considerations of a topic combined with suitable or unsuitable uses of a thinking process produce suitable or unsuitable conclusions and that this could take many forms. There seemed to be no definitive association among some topics and some thinking processes, whether suitable or unsuitable in either realm. Additionally, in this study, unsuitable applications of factual, procedural, and conceptual knowledge were not simply associated with the lack of these thinking processes; at times, the unsuitable thinking processes were present, deliberate, purposive, and not absent. Some of these findings disagree with prior research.

\section{Implications, Limitation, and Future Research}

The implications of this study are numerous and far-reaching. First, it may cause educators to reconsider the previously mentioned notion that factual knowledge $<$ procedural knowledge $<$ conceptual understanding. Second, it may be that we need to rethink what "errors" or unsuitable thinking means; it may be much more than a lack of particular types of thinking. Third, we need to reconsider the notion that simpler topics (i.e., angles $\leq$ measurement $<$ transformations $<$ constructions) are associated with lesser levels of thinking (i.e., factual knowledge $<$ procedural knowledge $<$ conceptual understanding) and vice versa. Fourth, this study may speak to the need for more studies regarding student use and misuse of these thinking processes regarding other mathematical subjects.

This research does not claim that the results would apply to all audiences of students. However, simultaneously, the authors find no reason to consider that the general findings would not be appropriate more broadly. This again speaks to the value of investigating these dimensions in different scenarios.

\section{REFERENCES}

[1] Anderson, L. W., \& Krathwohl, D. R, "A taxonomy for learning, teaching, and assessing: A revision of Bloom's Taxonomy of Educational Objectives," Longman. 2001, pp. 34-52.

[2] Baldwin, E. E., \& Yun, J. T, "Mathematics curricula and formative assessments: Toward an error-based approach to formative data use in mathematics," University of California Educational Evaluation Center Press, 2012, pp. 56-70.

[3] Biber, C., Tuna, A., \& Korkmaz, S, "The mistakes and the misconceptions of the eighth grade students on the subject of angles," European Journal of Science and Mathematics Education, vol 1, no 2, pp. 51-59. 2013.

[4] Bloom, B. S, "Taxonomies of educational objectives. Handbook 1. Cognitive Domain," McKay. 1956, pp. 97-115.

[5] Bogdan, R. C., \& Biklen, S. K, "Qualitative research for education: An introduction to theories and methods," (4th ed.), Allyn and Bacon, 2003, pp. 12-34.

[6] Brown, M., Bossé, M. J., \& Chandler, K, "Student errors in dynamic mathematical environments," International Journal for Mathematics Teaching and Learning, vol. 2, no, 4, pp. 67-78, 2016.

[7] Brown J., Skow K., \& the IRIS Center, "Mathematics: Identifying and addressing student errors," Retrieved May 16, 2016, from Retrieved from http://iris.peabody.vanderbi lt.edu/case_studies/ics_matherr.pdf accessed Jun. 1, 2020).

[8] Creswell, W. J, "Research design: Qualitative, quantitative and mixed methods approaches," (2nd ed.), Sage Publications. 2003, pp. 56-78.

[9] de Jong, T., \& Ferguson-Hessler, M. G. M, "Types and qualities of knowledge," Educational Psychologist, vol 31, no 2, pp.105-113, 1996.Doi.org/10.1207/s15326985ep310 2 2 2

[10] Fisher, D., \& Frey, N, "Making time for feedback," Feedback for Learning, vol 70, no 1, 42-46, 2012.

[11] Hunt, H. H., \& Little, M. E, "Intensifying interventions for students by identifying and remediating conceptual understandings in mathematics," Teaching Exceptional Children, 46, no 6, 187-196.

[12] Kingsdorf, S., \& Krawec, J, "Error analysis of mathematical word problem solving across students with and without learning disabilities," Learning Disabilities Research \& 
Practice, vol. 29, no 2, pp. 66-74, 2014. DOI. $10.1111 /$ ldrp. 12029

[13] Krathwohl, D. R, “A revision of Bloom's Taxonomy: An overview," Theory into Practice, vol. 41, no 4, pp. 212-218, 2002. Doi.org/10.1207/s15430421tip4104_2

[14] Miles, M. B. \& Huberman, M. N, "Qualitative data analysis: an expanded sourcebook," Sage, 1994, pp. 43-57.

[15] Özere, A, "Misconceptions in geometry and suggested solutions for seventh grade students," International Journal of New Trends in Arts, Sports \& Science Education, vol. 1, no 4, pp. 23-25, 2012. DOI:10.1016/J.SBSPRO.2012.09.5 57

[16] Pintrich, P, "The role of metacognitive knowledge in learning, teaching, and assessing," Theory Into Practice, vol 41, no 4, pp, 219-225, 2002. DOI.org/10.1207/s15430421ti p4104 3

[17] Powell, S. R, "Solving word problems using schemas: A review of the literature," Learning Disabilities Research \& Practice, vol 26, no 2, pp. 94-108, 2011. DOI.org/10.1177/0731948718823080

[18] Powell, S. R., Fuchs, L. S., Fuchs, D., Cirino, P. T., \& Fletcher, J. M, "Do word-problem features differentially affect problem difficulty as a function of students' mathematics difficulty with and without reading difficulty?" Journal of Learning Disabilities, vol 20, no 10, pp. 1-12, 2009. DOI.org/10.1177/0022219408326211

[19] Reys, R., Lindquist, M. M., Lambdin, D. V., \& Smith, N. L, Helping children learn mathematics" (11th ed.). John Wiley
\& Sons. 2015, pp. 40-56.

[20] Riccomini, P. J, "Identifying and using error patterns to inform instruction for students struggling in mathematics," Webinar slideshow. 2014, pp. 67-78.

[21] Rittle-Johnson, B., Siegler, R. S., \& Alibali, M. W "Developing conceptual understanding and procedural skill in mathematics: An iterative process," Journal of Educational Psychology, vol. 93, no 2, pp. 346-362, 2001. DOI.org/10.1037/0022-0663.93.2.346

[22] Shin, M., \& Bryant, D. P, “A synthesis of mathematical and cognitive performances of students with mathematics learning disabilities," Journal of Learning Disabilities, vol. 48, no 1, pp. 96-1, 2015.

[23] Stake, R. E. Case studies. In N. K. Denzin \& Y. S, "Handbook of qualitative research," (2nd ed.), Sage. 2000, pp. 67-89.

[24] Strauss, A., \& Corbin, J, "Basics of qualitative research," Sage Publications Ltd. 1990, pp. 89-97.

[25] Wodak, R, “Aspects of critical discourse analysis," Sage Publications. 2009, pp. 34-56.

[26] Wodak, R., \& Meyer, M, "Methods of critical discourse analysis," Longman. 2009, pp. 45-67.

[27] Vasileiou, K., Barnett, J., \& Thorpe, S. "Characterising and justifying sample size sufficiency in interview-based studies: systematic analysis of qualitative health research over a 15-year period." BMC Med Res Methodol 18, 2018 pp. 148-157. https://doi.org/10.1186/s12874-018-0594-7 